\title{
Changing Pattern of Disease and Disability in Schoolchildren in England and Wales*
}

\author{
PETER HENDERSON,† C.B., M.D.
}

Brit. med. F., 1968, $2,329-334$

\section{Handicapped Children}

One appreciates how much has been achieved in these islands when one visits a developing Asian or African country where there is still a mass of untreated physical disease among children, including tuberculosis, diphtheria, typhoid, virulent measles, the tropical diseases, and severe malnutrition. But already in these countries there are doctors and educationists who recognize that there are also boys and girls with emotional and behaviour problems, and with speech and language disorders, for whom there is no diagnostic, treatment, or special educational provision, and whose needs are submerged by the many with gross and grave physical illness. Recently I visited two of these countries, one in Africa the other in Asia, where there was only one psychiatrist in each. One of the countries had a single mental hospital with a nominal 700 beds for adults and children but, on average, 1,500 inpatients, more than half of whom had to lie on the stone floor of the wards. The other country had 100 psychiatric beds for an estimated population of about 12 million; patients, including children, who were considered to be "refractory" were sent to a home for the destitute.

Though such conditions no longer exist in this country we have no cause for complacency.

It must be emphasized that children with handicaps and disabilities do not often fall naturally into clear-cut separate categories. It is administratively convenient to have categories of handicapped children, but, in fact, many handicapped boys and girls have more than one disability; children with severe multiple handicaps, particularly those with grave defects of hearing and vision, present specially difficult problems to the medical, educational, and social services and, not least, to their parents. Parent counselling is vitally important but is outside the scope of this lecture.

Though most schoolchildren with severe handicaps and disabilities are in special schools quite a number attend the regular classes of ordinary schools, as do many children with less severe handicaps. There is still much to be learnt about what is the best educational provision that it is practicable to arrange for handicapped children, and the more closely the educational and medical services co-operate in this work the better it will be for the children and their parents. The official Ministerial policy is that "No handicapped pupil should be sent to a special school who can be satisfactorily educated in an ordinary school." 21

\section{Physically Handicapped Children}

The changing pattern of disease in schoolchildren is perhaps best seen in those with physical disabilities. In 1910 there were 863 children with tuberculosis of the bones or joints in the London day special schools for physically handicapped children; 39 were in the boarding special school in Manchester; in 1964 in all the special schools for physically

\footnotetext{
- Second Milroy lecture delivered at the Royal College of Physicians of London on 31 January 1968. The first lecture was published in last week's issue (p. 259).

t Principal Medical Officer, Department of Education and Science, London S.W.1.
}

handicapped children in England and Wales ${ }^{22}$ there were only 31-fewer than in Manchester alone 50 years ago. In all these schools there were only 76 boys and girls with rheumatic heart disease in 1964, whereas a generation ago there would have been more in any large city. Cerebral palsy now accounts for the largest group of children in schools for the physically handicapped, with spina bifida cystica second, congenital heart defects third, and muscular dystrophy fourth.

\section{Cerebral Palsy}

There are about 3,000 children with cerebral palsy in the special schools, several hundreds in small day centres, and many with slight or moderate disability in ordinary schools. In the past 20 years educational and medical provision for them was greatly expanded, including facilities for research. Both statutory and voluntary organizations shared in these developments, the work of the Spastics Society being specially notable.

The boys and girls in the special schools are seriously affected ; about $40 \%$ are also educationally subnormal; the hearing of from 10 to $20 \%$ is so defective as to be an additional educational handicap; visual defects are common, and inevitably many have severe speech and language disorders; and some are emotionally disturbed.

Such heavy and multiple disability almost defies treatment and seriously restricts educational progress. A few of these boys and girls do remarkably well, but the fact has to be faced that the majority of those in the special schools who are severely disabled will require family or community care for the rest of their days.

\section{Spina Bifida}

Rather less than 2 per 1,000 babies born alive have spina bifida. Up to about 1950 at least $90 \%$ of them died in infancy, but as a result of surgery in the first few hours of life, and improved medical and nursing care, nearly $50 \%$ now survive beyond 5 years of age. Most of them have hydrocephalus, many requiring ventriculo-cardiac drainage; most also have some interference with bladder control that often necessitates urinary diversion; only a minority do not need onthopaedic surgery.

These children will require skilled medical and nursing care right through their schooldays and beyond. Though many of them may be able to make satisfactory progress in ordinary schools, provided they are given proper medical supervision, it is inevitable that a substantial number need to be educated in special schools. The first special school solely for children with spina bifida was opened by the Shaftesbury Society, at Coney Hill, Kent, in 1959, largely on the initiative of Mr. Ellison Nash, who had long been specially concerned with their care; other special schools, and extensions to existing schools for the physically handicapped, are being built or planned to provide for the increased demand.

Much is to be learnt about the medical and social needs of these children as they grow older. What, for example, will 
be the effect on their personality and intelligence of repeated blockages of their Spitz-Holter or similar type valve? What will be the long-term effect of urinary diversion? These questions concern the surgeon as much as the physician; they certainly are of concern to the parents. And it must not be overlooked that the amount of treatment and medical supervision that these boys and girls require is already straining the treatment centres.

\section{Muscular Dystrophy}

There is no evidence that muscular dystrophy is increasing, but some of the affected children are living longer. Since the cause is unknown it is not surprising that there is no effective treatment. Recent research, however, seems to indicate that one or more enzymes may be missing from muscle cells. The discovery that the activity of serum creatinine kinase is increased in the majority of female carriers is of practical value in genetic counselling.

The total number of children involved is unknown; about 500 are so disabled that they are in special schools for the physically handicapped. Some, perhaps most, of the older ones know full well that their muscular weakness increases inexorably, and that they must go to some other institution when their schooldays are over. For those who cannot be cared for in their own homes on leaving school there is much need for more residential accommodation of suitable type: for a boy who enjoyed the amenities and diverse interests of a good boarding school abrupt transfer at the age of 16 years to a hospital ward for the chronic and sometimes aged sick must be a devastating experience. Some pleasant homes have been opened in recent years for physically handicapped young people, but more are required.

\section{Haemophilia}

Children with haemophilia comprise one of the smallest groups of physically handicapped children. Of the several hundred affected fewer than 200 are in special schools. There is increasing pressure from some doctors who are particularly concerned with the treatment of these children, and from some parents, for a residential special school solely for haemophilic children with a severe form of the disease, on the lines of those set up in France in the past 10 years. The provision of such a school is now being considered.

A survey ${ }^{23}$ in 1965 showed that haemophilic children lost much school time and that there was little liaison between schools and haemophilia centres. The recent introduction of cryoprecipitate, provided it is used promptly when bleeding starts, is likely to reduce substantially not only the crippling that has been such a tragic incapacitating factor in the lives of so many haemophiliacs but also the amount of school time lost through repeated haemorrhages. The full value of this new method of treatment will not be obtained unless there is a close round-the-clock working arrangement between the treatment centres, the parents, and the schools. There is, in fact, a close parallel between the need for special centres for the management and treatment of haemophiliacs and centres for the management and treatment of diabetics.

\section{Diabetes}

Various estimates have been made of the number of diabetic schoolchildren. A detailed inquiry in Northamptonshire in 1963 by Dr. J. A. A. Reid showed that 1 in 1,600 children were known to be diabetic. On this evidence there are about 4,000 to 4,500 diabetic schoolchildren. Practically all of them are able to attend ordinary schools; about 100 are in four special hostels, from which they go out to school. The first hostel was opened in 1939 by the London County Council, largely on the initiative of the British Diabetic Association, as part of the evacuation scheme. It was so successful that when the war ended five other hostels were opened by the Church of England Children's Society and the National Children's Home at the invitation of the Ministry of Education. Subsequently, however, two were closed owing to lack of demand. The aim of these hostels, which are under expert medical and nursing supervision, is to teach the children the diabetic way of life, to help them develop into self-reliant young people with full knowledge of all that being a diabetic entails, and that this should not limit their enjoyment of life or prevent them from taking a full part in the community when they become adults.

One of the notable results of hostel care and training is that it is rare for any of the children to be sent to hospital on account of their diabetes. This is a very different experience from that disclosed by the inquiry into patients discharged from hospitals in 1963, when it was estimated that there were about 1,800 discharges of diabetic children aged 5-14 years from hospitals that year. Even allowing for new cases, and for children in and discharged from hospital more than once during the year, this was a large percentage of the total number of diabetic children.

There has been no systematic follow-up of the children discharged from hostels to find out if the care and training they received have reduced or delayed the dreaded later complications of diabetes: this is an inquiry that would be worth making.

\section{Epilepsy}

There is perhaps more uncertainty about the total number of epileptic schoolchildren than about any other disability in childhood. What is certain is that the number-1.2 per 1,000 in 1965-found at periodic school medical examinations is only part of the total. Occasional nocturnal or minor disturbances at home are often not disclosed to school doctors, but seizures in school are unlikely to pass unnoticed. Most epileptic school. children attend ordinary schools, and though the school population is rising the number of children in the six special schools for epileptics remains about 650 . Sometimes there is justifiable complaint that children are sent to these schools too late: It would be wrong, however, to deduce from this that many epileptic children are wrongly placed in ordinary schools.

There is no doubt that the treatment of epileptic schoolchildren has improved in recent years and that more ordinary schools are now willing to retain them. Most of the boys and girls in the special schools for epileptics (which are among the best special schools in this country) have more than epilepsy to contend with; many are seriously retarded and a substantial number are emotionally disturbed or have other handicaps.

Epilepsy is a continuing serious hazard to the health and well-being of children. Though it was one of the earliest known pathological conditions, and one that has despoiled countless children and adults throughout the centuries, its primary cause is still unknown.

\section{Blind and Partially-sighted Children}

Blind.-The number of children at schools for the blind fell from 1,508 in 1934 to 1,038 in 1953 and then rose to 1,300 in 1960 and fell to 1,218 in 1966 . The reduction between 1934 and 1953 was due mainly to the prevention of ophthalmia neonatorum and the control of other infections that gave rise to blindness. The rise between 1953 and 1960 was caused by a sudden increase in the number of premature babies who developed retrolental fibroplasia in the years 1949-53; shortly all these children will have left the special schools, when the number of blind children in them is expected to be below 1,000. Not all blind children are at school, since some are also severely 
subnormal and are considered at present to be unsuitable for education at school; this is particularly the case with some blind and some partially-sighted children who are also deaf or partially-hearing, whether from maternal rubella or other cause. The chief causes of blindness in schoolchildren are optic atrophy, closely followed by congenital cataract ; together they account for almost half the children now at schools for the blind.

Partially-sighted Children.-In 1966 2,033 children attended special schools or special classes for the partially sighted. The first special class was opened in London in 1908 as a sightsaving class for myopes. It is now known that these classes do not "save" sight, but they do help some children with severe visual loss to derive more educational benefit than they would do if they attended the regular classes of ordinary schools. Cataract is the chief cause of partial sight in the children who attend special schools and classes, myopia being the second and optic atrophy the third.

\section{Deaf and Partially-hearing Children}

As a result of earlier diagnosis, the provision of hearingaids, and the instruction of parents many children who 20 to 30 years ago would have been regarded, and taught, as deaf are now educated as partially-hearing. Perhaps the most crucial development in recent years in the management of children with defective hearing has been the persistent efforts to diagnose deafness in infancy and then to exploit fully the affected child's residual hearing and his capacity to listen to sounds and speech. A child's mother is his earliest teacher, and she has the opportunity, granted to no one else, to talk to him close to his ears, day in, day out.

Screening tests of the hearing of infants and young children are now the rule throughout the infant welfare service, and every child found with, or suspected to have, defective hearing is referred to audiology clinics for diagnosis and assessment. An increasing number of these clinics have the services of trained teachers of the deaf who are invaluable in helping in the assessment of a child's hearing for speech and language development.

Many schoolchildren have an audiometric test of their hearing when they first start school; this is essential, since about $80 \%$ of them ceased attending infant welfare clinics at about the age of 2 years.

The Education Act of 1944 made it the duty of local education authorities to ascertain handicapped children in need of special educational treatment from the age of 2 years, though school attendance is not compulsory until the age of 5 years. It is now generally appreciated that the diagnosis of defective hearing should be made, and auditory training started, before the age of 2 years. It was not until 1945 that separate definitions were given, in Regulations made under the Education Act of 1944, of " deaf" and "partially-deaf" pupils for the purposes of education. In 1962 the Regulations were amended to substitute " partially-hearing" for "partially deaf." When it is remembered that it was not until 1938 that the age of compulsory school attendance for deaf children was lowered from 7 to 5 years it will be realized how different our attitude now is to the whole subject of defective hearing in children; and for this changed attitude we owe much to the late Miss Edith Whetnall and to Sir Alexander and the late Lady Irene Ewing.

In 1947 the London Education Authority established special classes in ordinary schools for partially-hearing children; by 1966 there were about 150 such classes in England and Wales, with just over 1,000 children. Teachers of the deaf have been appointed to a number of special schools for the physically handicapped where there are children who are partially hearing as well as physically disabled.

Another recent development was the provision by local education authorities of a peripatetic teacher service that enables trained teachers of the deaf to visit ordinary schools without special classes but where there are children with defective hearing; some of these teachers also work in audiology clinics. Yet another recent advance was the opening in 1966, by the Royal National Institute for the Deaf, of a special boarding school at Stokes Poges, in Buckinghamshire, for deaf children with severe emotional and behaviour difficulties.

As a result of these various developments fewer children are taught as deaf but more as partially-hearing. In 1908 about 3,500 children ( 7 per 10,000 school population) were educated in schools for the deaf; in 1957 about 3,700 (5.5 per 10,000) were taught as deaf and about 1,300 (1.9 per 10,000) as partially-hearing, while in 1966 about 3,200 (4.4 per 10,000) were taught as deaf and about $3,600(5.1$ per 10,000) as partially-hearing.

All this is sheer gain, but we would be deluding ourselves if we believed that all is now well with the education of deaf children. The educational separation of the partially-hearing from the deaf has made even plainer the gravity of profound deafness and the heavy barrier it raises against a child's development of speech and particularly language. A survey ${ }^{24}$ of older boys and girls in schools for the deaf showed that only $22 \%$ of them had intelligible speech; $23 \%$ had speech that was completely unintelligible and $55 \%$ had speech that varied from barely to fairly intelligible; most of them were also seriously retarded in their language development. In 1964 the Secretary of State for Education and Science appointed a committee to investigate the place, if any, of manual means of communication in the education of deaf children. The committee's report $^{25}$ will shortly be published.

It is becoming increasingly apparent both in this and in other countries that some children in schools for the deaf have a disorder that involves more than the auditory pathway; there is much still to be learnt about "central deafness" and its relation to "congenital dysphasia" or " congenital auditory imperception," or whatever term is used to describe the condition. The Manchester Education Authority recently opened a small special school for the study, investigation, and education of this type of child; it is expected to work closely with the Department of Audiology and Deaf Education of Manchester University and with the neurological department of Booth Hall Children's Hospital. Children with severe disorders of speech and language form a larger and more complex group than was formerly supposed, and their study and management involves a close working partnership between doctors, psychologists, and teachers.

\section{Speech and Language Disorders}

The Manchester Education Authority was the first to provide treatment for children with speech disorders; in 1906 it arranged for the treatment of stammerers, but it was not until the coming into force of the Education. Act 1944 that local education authorities were given the duty of ascertaining which children in their area required special educational treatment for speech defect.

In 1947 the first special school for the study, education, and treatment of children with speech disorders was opened at Moor House, Oxted, Surrey, largely on the initiative of Dr. Worster-Drought, who had long been convinced that children with the diagnosis of "congenital dysphasia" or "congenital auditory imperception," as well as some with other speech disorders, could not be treated adequately in the outpatient department of a hospital; he was equally convinced that for these children treatment and education should go hand in hand. In 1958 a second special school for children with speech defect was opened at the John Horniman Home, Worthing, by the Invalid Children's Aid Association.

A third special school, the Edith Edwards Home School, was opened, also by the I.C.A.A. at the invitation of the Ministry of Education, first at Hove in 1962 and then transferred to

\section{.}


permanent premises at Banstead, Surrey, in 1964, for the education and treatment of children with difficulty in communication and who were also emotionally disturbed. The need for this type of school became plain from the experience gained at Moor House School and at Dr. Minski's unit at Belmont Hospital, Surrey.

Recently, special classes for children with speech disorders have been started in a few ordinary schools.

While these special school developments were taking place there was a substantial increase in the number of children with speech defects treated at local education authority speech therapy clinics; by 1966 the number was just over 57,000. There is a national shortage of practising speech therapists (due mainly to therapists leaving the service on marriage) that is reflected in the patchy distribution of treatment facilities.

A survey ${ }^{26}$ of 1,7005 -year-old children in the schools of Leicester City in 1965 showed that $12 \%$ had minor speech disorders and $2.7 \%$ an obvious speech defect; only one child stammered. There have been reports from some other areas that fewer children than formerly stammer.

Speech and language disorders are also a prominent feature of severely retarded, psychotic, and "autistic" children.

\section{Educationally Retarded and Educationally Subnormal Children}

More than half of all the handicapped children who receive special education are in schools for the educationally subnormal, and many of those in other types of special school are also severely retarded educationally. A survey of all the special schools for physically handicapped children in 1964 showed that about $40 \%$ of those with cerebral palsy were also thought to be educationally subnormal.

Various estimates have been made of the percentage of educationally retarded children in ordinary schools; about $10 \%$ would not be an overestimate (after making full allowance for the report $^{27}$ that, in 1964, 11-year-old boys and girls had reached the reading standard achieved in 1948 by boys and girls who were 17 months older).

A study ${ }^{28}$ of 8,000 children in Kent showed that $19 \%$ had scarcely begun to read by the age of 7 years; 700 of them were then investigated thoroughly, when it was found that $14 \%$ could not read by the age of 8 years, and $7 \%$ were backward or semi-literate when they left school.

The many reasons for backwardness in reading include: slow maturation, sensory defects, misperception of letters or numbers, emotional disturbance (may also result from reading difficulty), homes that give no incentive or encouragement to children to read, and indifferent teaching.

For many years there has been argument between some neurologists and psychologists on whether or not there is such a condition as "specific developmental dyslexia." The psychologist who made the study of Kent children was emphatic that "the poorest readers were not in any reasonable interpretation of the term a neurological problem, and that the study as a whole lends little support to the idea that 'specific developmental dyslexia' is an identifiable syndrome distinct from "reading backwardness." " 28 The Plowden Committee was also sceptical but expressed a more cautious opinion: "It is difficult to be sure whether specific dyslexia exists as an independent factor. An acute difficulty in reading appears to be confined to a very. small number of children, perhaps five or fewer in a thousand," 29 but this would mean up to 40,000 schoolchildren.

However stimulating these intellectual arguments, they ought not to obscure the plain fact that many schoolchildren are backward readers from a variety of causes and that they require early-and skilled individual teaching help ; increasing attention is being given to them but much more remains to be done. There are now a number of centres for the study and treatment of children said to have specific developmental dyslexia, including one at St. Bartholomew's Hospital, and another at the Word Blind Centre, Coram's Fields, London, provided by the Invalid Children's Aid Association.

There is still much to be learnt about the learning difficulties of children and how best to teach them; their elucidation will depend on joint investigation by teachers, psychologists, and doctors working together and mainly in an educational setting.

\section{Severely Subnormal Children}

Over 30,000 children of school age are at present outside the educational system on account of severe subnormality; in 1966 over 17,000 were at local health authority training centres, about 7,000 were in subnormality hospitals, and about 6,000 at home. In 1957 the Report of the Royal Commission ${ }^{30}$ recommended that administrative responsibility for the junior training centres in England and Wales should remain with local health authorities and not be transferred to local education authorities. Since then, however, there was increasing support for those who advocated this transfer of responsibility.

The whole trend has been towards bringing all retarded children together as an educational entity, with variety of provision and elasticity of administrative arrangements. The doctor has a very definite place with his educational colleagues both in the investigation of the various difficulties of these children and in advising local education authorities, teachers, and parents on their management. It must be emphasized, however, that responsibility for deciding the type of educational arrangement most appropriate for handicapped children rests with the local education authority ; this is primarily an educational matter.

\section{Children with Emotional and Behaviour Difficulties}

The improved physical health of schoolchildren in the past 50 years, and the expansion of medical services for them, have thrown into sharp relief the large number with emotional, behaviour, and learning difficulties who need skilled help and guidance. But even 50 years ago this need was understood by those who had the vision to see the nature of the problem. It was as early as 1913 that the London County Council, the first local education authority to do so, appointed a psychologist, Mr. Cyril Burt. At that time, too, Dr. Hector Cameron was making his notable study at Guy's Hospital of "nervous" children, and his book, The Nervous Child, had wide and profound influence. In 1920 the Institute of Medical Psychology (the Tavistock Clinic) was established in London, and it was by sheer chance that a child was its first patient. In 1927 the Jewish Health Organization opened the East London Child Guidance Clinic, the first to be set up in this country. In 1932 the first special school for maladjusted children was opened by the Leicester Education Authority. But by 1939 only 22 child guidance clinics had been provided by local education authorities and a few others by voluntary organizations and hospitals.

This service developed slowly, often against scepticism and, indeed, cynicism. The mass evacuation of children from towns early in the second world war quickly brought demands for hostels for those children whose behaviour made them "unbilletable," and for psychiatric and psychological help for them. In the next six years the number of child guidance clinics increased to 79 ; by 1966 they numbered 403 (341 being provided by local education authorities) and were attended by 55,000 children. In 1966 , also, about 8,000 boys and girls were at special or independent schools, in special classes, or in special boarding homes on account of maladjustment. Special schools increased from 13 in 1959 to 93 in January 1968. Another recent development was the setting up of special classes in ordinary schools, and by January 1966 there were 108 such 
classes attended by over 400 children whole-time and about 900 part-time. Unfortunately, owing to a chronic shortage of psychiatrists, psychologists, and social workers the service is unevenly distributed; in 1965 the ratio of children treated to school population was 1 in 134, but the range was from 1 in 21 to 1 in 7,800 .

The development of provision for maladjusted children is an indication that the emotional needs of boys and girls are now more widely understood not only by teachers, psychologists, and doctors but by parents and education authorities.

About $9 \%$ of all the students at one of the largest of English universities consulted the student health service in 1965 on account of emotional or psychological problems, many of which were slight but some were serious. Mental illness accounts for about $50 \%$ of all the illnesses that interrupt the studies of university students by more than two months. There is evidence that some of the psychological difficulties of students can be traced back to their schooldays and often to their home circumstances. It is noteworthy that less than $20 \%$ of the boys and girls who attend child guidance clinics are from secondary schools. More thought needs to be given to the preparation of future students for the wider and freer life of university and college during their last year or two at school.

There is also much need for more knowledge of how maladjusted boys and girls-and, indeed, all handicapped children -fare when they leave school. A study ${ }^{31}$ of 32 children during the five years after they left a special school for maladjusted children at the age of 16 years showed that only five had made a good adjustment to adult life, six were "coping," but 21 had broken down emotionally or had become delinquent. No generalization can be made from this small study except that it pointed the need both for more knowledge of what becomes of maladjusted and, indeed, all handicapped children when their schooldays are over, and for practical support for at least some of them during the transition period from leaving the sheltered environment of a special school and establishing themselves as adults in the thrusting outside world.

Though many of the children who attend child guidance clinics are mildly disturbed some are severely affected, including some who are psychotic or autistic.

\section{Psychotic or Autistic Children}

This condition becomes apparent in infancy or early childhood, and more boys are affected than girls. The chief characteristic is a serious deficiency in the children's ability to make emotional relationships, particularly with other boys and girls; they remain aloof from their group, often clutching an inanimate object, and living in a world of their own. They resent and resist changes in their environment. Most of them have odd mannerisms ; some are hyperactive ; others are aggressive or do themselves injury. Many are, or function as, mentally subnormal, but some are of normal intelligence. Their speech and language development is delayed and of ten abnormal. In consequence they are often unusually poor performers in activities involving the use of language, but they may do better than expected in non-verbal ones. Many show signs of brain damage.

A survey ${ }^{32}$ in Middlesex in 1964 suggested that there were probably about 3,000 autistic children in England and Wales. They may be in mental or subnormality hospitals, at local health authority training centres, in small classes or schools provided by local education authorities or voluntary organizations, or at home. They present difficult educational, medical, and social problems, and their prognosis is often uncertain. There is need for more study of and more educational provision for them. Dr. M. Rutter, of the Institute of Psychiatry of the Maudsley Hospital, with financial support from the Department of Education and Science, is now studying the progress of a number of these children in three different educational environments.

\section{"Brain-damaged " Children}

This is a frequently used but misleading term as, even with the best diagnostic means now known, there is usually no definite clinical evidence of brain damage. There is an increasing tendency to describe them as children with minimal cerebral dysfunction, since their maturation is unduly delayed. They may be unusually clumsy, overactive, easily distractable, have difficulty in the perception of shapes, and so are retarded in reading and often in speech; they may be aggressive or below average in intelligence. An affected child may have one or more of these characteristics. They are a nuisance to their companions, a problem to their teachers, and a worry to their parents. They present a wide field for educational, medical, and psychological research, and they all need help.

\section{Delinquent Children}

It is sometimes said that it is pure chance whether a child who is caught stealing ends up in an approved school or in one for maladjusted children. Between 1938 and 1965 the number of boys under 17 years of age found guilty of indictable offences (mainly larceny and breaking and entering) increased from 26,369 to 55,194 and the number of girls from 1,745 to 7,676. Most juvenile delinquents are convicted once only: a minority become persistent offenders. The "success rates" of approved schools (those who were not guilty of any offence during the three years after leaving an approved school) have been falling; it was $66 \%$ for seniors in 1949 but only $46 \%$ in 1959 ; for juniors the rates were $58 \%$ in 1949 and $38 \%$ in 1959. In explanation of these reduced "success rates" it was said $^{33}$ that more children convicted of less serious offences were put on probation or were sent to attendance or detention centres instead of to approved schools, and that more of the boys who were admitted to the schools were "more disturbed and less responsive to training" than those who were sent to them before 1939.

There is much need for more study of those who become delinquent, of their home circumstances, and of the methods used to deal with them. There is as strong a case for the school health and hospital paediatric services to study the children at risk of developing emotional or behaviour difficulties as there is for studying children at risk of having physical defect or disease. The reduction of delinquency by preventive measures, difficult though these may prove to be, would be more rewarding than trying to treat the delinquent. High among those at risk are the children who are desperately in need of affection and the security that can be found only in the warmth of a united family.

\section{Children in Care of Local Authorities}

In March 1967 there were almost 70,000 children in the care of local authorities, about 15,000 being under, 15,000 over, and 40,000 of compulsory school age. Almost 30,000 were in temporary care on account of the confinement of the mother or illness or parents or guardian. ${ }^{34}$ Of the other 40,000 no fewer than 8,000 were in care because they had been deserted by their mother, were abandoned or lost, or their parents or guardians were dead or in prison, or the mother was dead and the father unable to care for them ; another 5,000 were homeless or had very unsatisfactory home conditions; and about 3,000 were illegitimate, with a mother who was unable to provide for them. These grim figures conceal a mass of human misery that is as tragic as it is deplorable. The wonder is that more of these children do not become antisocial as they grow older. And, too, there are the complex social, educational, and medical problems that stem from divided homes. Often they may seem intractable ; they are likely to be with us for a long time, but their containment and reduction will depend on 
concerted action by the education, medical, and other social services.

\section{Interdependence of Educational, Medical, and Social Services}

Much has been achieved in the control of physical disease and in the improvement of economic and social conditions; indeed, the one very largely depends on the other. The layman has been, and will continue to be, as indispensable in medicine as the doctor is in education and in the other social services; all the social services would be impotent without the politician -sufficient proof of this is that public expenditure on education amounted to about $£ 1,800 \mathrm{~m}$. in the United Kingdom in $1966,{ }^{35}$ and on the health and welfare services provided through the Ministry of Health to just over $£ 1,240 \mathrm{~m}$. in the year ended 31 March $1966 .^{36}$

The development of the child health and public health services of this country is a living example of the interrelationship of medical, social, and educational factors in the promotion of health in all its aspects. Many of the problems of child health that still confront us will not be solved by doctors alone; and certainly not if they work apart in hospitals and medical clinics.

Whatever administrative changes may be made in the organization of the education, health, and social services it is essential that doctors concerned with children, whether in the home, in hospitals, or in schools, should work together and in close partnership with the teachers, the other social workers, and the parents.

All doctors who deal with children should be specially knowledgeable about their emotional, behaviour, and educational difficulties, and proper account should be taken of these during their undergraduate and postgraduate training. None. of the postgraduate diplomas up to the present, at any rate, has done this, and there is, unfortunately, strong evidence ${ }^{37}$ that undergraduate training in paediatrics is not up to standard in many medical schools in this country.

The words that Dr. Hector Cameron wrote 50 years ago are as true now as they were then: "More and more a considerable part of the Profession must busy itself in nurseries and in schools, seeking to apply there the teachings of Psychology, Physiology, Heredity, and Hygiene." 38

This is the fundamental task of health education, and is one that concerns us all. We shall continue to make mistakes, but surely we have at least learnt, to quote the eloquent words ${ }^{39}$ of Sir Arthur Bryant, that " neither wealth nor power nor comfort, whether for class or individual, are ends in themselves: that the wealth of a nation consists in nothing but the virtue of her children and her children's children. That no profits, education, law, custom, or institution that does not contribute to their health and goodness is of any enduring value."

\section{REFERENCES}

21 Ministry of Education Circular No. 276, 1954. H.M.S.O., London.

22 Department of Education and Science, Health of School Child, $1964 / 5,1966$, p. 52 . H.M.S.O., London.

23 Britten, Margaret I., Spooner, Rosemary J. D., Dormandy, Katherine M., and Biggs, Rosemary, Brit. med. $7 ., 1966,2,224$.

${ }_{24}$ Department of Education and Science, Health of School Child, 1962/3, Depariment of Education and Science, Heal
1964 , pp. 60-71. H.M.S.O., London.

25 Report of Committee on Finger Spelling and Signing in Education of the Deaf, 1968. H.M.S.O., London. In press.

${ }^{26}$ Health of School Child, 1964/5, 1966, p. 36. H.M.S.O.. London.

27 Peaker, G. F., Standards of Reading of Eleven Year Olds, 1948/64, Appendix 7, Children and Their Primary Schools, 1967, vol. 2. H.M.S.O., London.

28 Morris, Joyce M., Standards and Progress in Reading, 1966, p. 303. National Foundation for Educational Research, Slough

29 Department of Education and Science, Children and Their Primary Schools 1967 ducaton and Science, Chldren and

so Report of Royal Commission on Law Relating to Mental Illness and Mental Deficiency, 1957. H.M.S.O., London.

$s_{1}$ New Society, 1964, 3, No. 72, p. 20 .

32 Wing, J. K., O'Connor, N., and Lotter, V., Brit. med. F., 1967, 3, 389

s3 Home Office Report on Work of Children's Department, 1961-63, 1964. H.M.S.O., London.

${ }^{4}$ Children in Care in England and Wales in 1966, 1967. H.M.S.O.

35 Report of Department of Education and Science, Education in 1966, 1967, p. 9. H.M.S.O., London.

${ }_{36}$ Ministry of Health, Annual Report of the Ministry of Health for the Year 1966, 1967, p. 6. H.M.S.O., London.

${ }^{37}$ Jackson, A. D. M., Brit. F. med. Educ., 1966, 1, 25

${ }^{38}$ Cameron, H. C., The Nervous Child, 1919, p. V. London.

39 Bryant, A., English Saga, 1945, p. 334. London.

In addition to the above, extensive use made of the Registrar General's Statistics Review for England and Wales for each year up to 1965 , Pt. 1, Tables, Med., H.M.S.O., London, and the Annual Reports of C.M.O., Board of Education, from 1908 onwards. H.M.S.O., London.

\section{Case 1}

The patient, a 12-month-old girl, was admitted to hospital in November 1967. Two weeks previously she had had a mild upper respiratory tract infection which settled without special treatment. For four days before admission she had been feverish and restless, and for two days had held her right hip flexed and had been reluctant to take weight on the right leg.

On examination she was pyrexial $\left(38.5^{\circ} \mathrm{C}\right.$.) and irritable, and the pulse rate was 170 . She had a tendency to lie in an opisthotonic position though there was no other evidence of meningism. The right hip was partially flexed and lumbar scoliosis concave to the right was present. There was no local tenderness over the right hip or femur. The hip movement was slightly limited in rotation and extension, but was not painful.

Investigations.-Haemoglobin $77 \%$; E.S.R. $129 \mathrm{~mm} . / \mathrm{hour}$; white blood count $23,000 \mathrm{cu}$. mm. ( $84 \%$ neutrophils). Serum electrolytes were normal. Three separate blood cultures were taken. $X$-ray examination showed an effusion of the right hip, confirmed the presence of the lumbar scoliosis, and was suggestive of a mass in the right loin.

* Central Microbiological Laboratories and Paediatric Unit, Northern Group of Hospitals, Edinburgh. 